\title{
An evidence-based warfarin management protocol reduces surgical delay in hip fracture patients
}

\author{
M. Diament ${ }^{1}$ W. G. P. Eardley ${ }^{1}$
}

Received: 3 December 2014/Accepted: 23 April 2015/Published online: 15 May 2015

(c) The Author(s) 2015. This article is published with open access at Springerlink.com

We read with interest the work of Ahmed et al. [1] regarding anticoagulation reversal in the hip fracture population. Whilst congratulating the authors on the clarity of their protocol, we would like, if we may, to highlight a number of areas we feel require further explanation.

Hip fracture care in the United Kingdom (UK) has been transformed in recent years. Care is now optimised through best practice tariffs (BPT), a financial incentive scheme that advises, amongst other domains, that patients with a hip fracture undergo surgery within $36 \mathrm{~h}$ of admission [2]. Ahmed et al. work within this system in the UK. Time to surgery is a major driver of care and is the subject of contemporary literature [3]. It is concerning, therefore, that there is no mention of the performance of their population in terms of the biggest outcome assessment used in UK trauma care. This omission is puzzling. Also, despite current guidelines advising that time to theatre should be within $36 \mathrm{~h}$, the authors ignored this and chose $48 \mathrm{~h}$ instead.

Having used a 48-h outcome, Ahmed et al. state that $80 \%$ of their cases achieved surgery within this time frame. The raw data, however, do not support this. The authors state that 21 of their patients required more than one dose of IVK. Following their flow chart, these 21 patients would, once in receipt of their second dose of IVK, have waited a further $24 \mathrm{~h}$ before having their INR

Note from the Editorial Office: the present Letter is published without any reply since the Authors of the original article did not answer despite several solicitations. Should the Authors decide to reply, JORT will publish their clarifications.

W. G. P. Eardley

willeardley@googlemail.com; willeardley@doctors.org.uk

1 Department of Trauma and Orthopaedics, James Cook University Hospital, Middlesbrough, UK rechecked. Put simply, 21 of 40 patients waited at least $48 \mathrm{~h}$ before being in a position to be considered for surgery, never mind actually having an operation. With over $50 \%$ of patients unable to reach a decision point on fitness to operate until at least $48 \mathrm{~h}$, how can they conclude that $80 \%$ of the same population had an operation within the same time period?

There are a number of other issues with this study. There were apparently no patients in either group that were cancelled or delayed to theatre for reasons other than warfarin reversal. Ahmed et al. indicate that this is the case, as there is no disclosure of comorbidities (unwell patients requiring optimisation prior to surgery) or logistic delays (inability to access the trauma theatre due to caseload). These two elements are the biggest challenges to timely hip fracture care in clinical practice.

The wider readership and particularly those of us practising in the United Kingdom would benefit from some clarity on the above points. This would help hip fracture units decide on whether or not to adopt this protocol in light of the data discrepancies above and the impact this may have on BPT revenue.

Open Access This article is distributed under the terms of the Creative Commons Attribution 4.0 International License (http://crea tivecommons.org/licenses/by/4.0/), which permits unrestricted use, distribution, and reproduction in any medium, provided you give appropriate credit to the original author(s) and the source, provide a link to the Creative Commons license, and indicate if changes were made.

\section{References}

1. Ahmed I, Khan MA, Nayak V, Mohsen A (2014) An evidencebased warfarin management protocol reduces surgical delay in hip fracture patients. J Orthop Traumatol. 15(1):21-27 
2. British Orthopaedic Association. Payment by results and best practice tariff. London, United Kingdom: British Orthopaedic Association; 2013 (updated 29 December 2013; cited 30 December 2013). Available from: http://www.boa.ac.uk/LIB/LIBPUB/Pages/ PbR.aspx

3. Al-Ani AN, Samuelsson B, Tidermark J et al (2008) Early operation on patients with a hip fracture improved the ability to return to independent living. A prospective study of 850 patients. J Bone Joint Surg Am 90(7):1436-1442 